\title{
Need for Service Design Development for Sustainable Rural Tourism in Azerbaijan
}

\author{
Jonna Heikkilä \\ Faculty of Technology, Environment and Business, \\ Turku University of Applied Sciences Ltd. \\ Sepänkatu 1 , \\ Turku 20700, Finland \\ E-mail: jonna.heikkila@turkuamk.fi \\ Aytan Poladova \\ Ekoloji Tarazliq NGO \\ Besir Seferov str. 22, 05, \\ Baku, Azerbaijan \\ E-mail: apoladova@ewmi-seda.org \\ Juha Kääriä \\ Faculty of Technology, Environment and Business, \\ Turku University of Applied Sciences Ltd. \\ Sepänkatu 1, \\ Turku 20700, Finland \\ E-mail: juha.kaaria@turkuamk.fi
}

Abstract: 'Development of Sustainable Entrepreneurship and Support of Local Handicrafts in Rural Azerbaijan' is a joint effort between the Turku University of Applied Sciences Ltd. and Sustainable Future in Finland and Ekoloji Tarazliq NGO as a local partner, with the aim of creating rural businesses and services in order to attract tourists to the three project areas. Thus far, most of the tourists in Azerbaijan have been business travellers staying in the capital, Baku. The project (implemented in 2012-2014) has introduced PPP or public-private partnership approaches in the promotion of sustainable tourism through the involvement of various stakeholders from small-scale entrepreneurs to national level authorities. The most important stakeholder groups are the local communities, entrepreneurs, handicraft masters, and owners of households providing accommodation services to travelers. 
Several challenges and areas of development in rural tourism have been identified: insufficient infrastructure in rural areas, varying quality of services, and unclear brands of different regions. Rural tourism has great potential in Azerbaijan, but it needs promotion and support, especially in organized structures for service design and marketing channels, which require strong cooperation on the national and local level.

The project envisages eco-cultural tourism as a concept which emphasizes unique environmental conditions and traditional cultural values in order to create favorable conditions for tourists; meanwhile it presents marginal livelihoods a novel source of income. Sustainability and participation are crucial for the long-term future of eco-cultural tourism, which could, with strong multilevel cooperation and comprehensive service design structures, promote economic development and support especially women's participation and role in the tourism market of the rural areas.

Keywords: Azerbaijan, eco-cultural tourism, entrepreneurship, rural tourism, service design

\section{Background}

Tourism is one of the largest and fastest growing industries in the world (Irshad, 2010). In both developed and developing countries, tourism is frequently supposed to be a viable means of raising the economic activity of regions (Ying, 2007, p. 96). Additionally, the development of tourism industry has been noted to promote the destination's image, enabling the region to achieve other objectives, such as business recruitment and retention. According to the World Travel and Tourism Council, tourism generates 12 per cent of the global Gross National Product and it employs around 200 million people worldwide. Tourist arrivals are estimated to increase 1.6 times by 2020 worldwide (World Tourism Organization, 2013, pp. 10-12). Out of the 20 most visited long-haul tourist destinations, 14 are located in developing countries. Approximately 80 per cent of the travelling tourists are from 20 developed countries such as Japan, USA, Canada, and 17 countries of Europe (Sustainable Travel International, n.d.).

Sustainable tourism can be defined with reference to Brundtland's report (1987) in which sustainability refers to the use of resources in a way that answer to the needs of the present, without compromising the ability of future generations 
doing the same (United Nations, 1987, p. 15). Furthermore, sustainable tourism calls for local cooperation between public administration, private sector, the local communities and the tourists themselves (World Tourism Organization, 1998, p. 19). Ecotourism (or eco-cultural tourism) can be perceived as a subcategory of sustainable tourism, defining it as

environmentally responsible tourism that involves travel $[\ldots]$ to relatively undisturbed natural areas with the object of enjoying [...] the nature, as well as any cultural aspect found [...], through a process which promotes conservation, has a low impact on the environment and on culture and favors the active and socioeconomically beneficial involvement of local communities (Ecotourism in America, n.d.).

However, this definition has yet to reach a universal consensus taking in consideration other definitions which co-exist (e.g., Weaver \& Lawton, 2007, p. 1170; Donohue \& Needham, 2006, p. 192; Higham, 2007; Cater, 2001, p. 4166).

Another term often referred to in the discourse of sustainable tourism or ecotourism, is rural tourism. Rural tourism is difficult to define extensively, due to its correlation with the country or specific regional environment, culture and activities. The distinctive feature of rural tourism is said to be "the desire to offer visitors a personalized treatment, giving them the opportunity to enjoy the physical and human environment of rural areas, and, as far as possible, take part in the activities, traditions and lifestyles of local communities" while "it contributes to the economic and social recovery of the rural areas, as well as to the conservation of the environment and the spreading of local cultures" (Ecotourism in America, n.d., see also Dimitrovski et al., 2012, p. 289, European Parliament, 2013, p. 19).

\section{Project introduction}

In 2012 Turku University of Applied Sciences (TUAS) initiated a project called 'Development of Sustainable Entrepreneurship and Supporting of Local Handicrafts in Rural Azerbaijan,' in cooperation with Sustainable Future NGO from Finland and Ekoloji Tarazliq NGO as the local partner. Long-term objectives of the project include the development of ecotourism approaches, promotion of business, poverty reduction and sustainable development of rural and remote areas of Azerbaijan. The target groups of the project have consisted of local entrepreneurs of the project regions such as handicraft workers, home accommodation providers 
and other stakeholders of the field with special emphasis on rural women. The project is funded by the Ministry for Foreign Affairs of Finland.

Azerbaijan is a region with unique geographical, geopolitical, and climatic conditions. There are nine different climate zones and plenty of medical, mineral and thermal springs. Additionally, twelve reserves and six national parks have been established, which constitute 2.4 per cent of the territory of the republic (CESD, 2011, p. 4). Azerbaijan is often called "the pearl of the Middle East". This former Soviet Republic has become one of the most attractive tourist destinations in the Caspian Sea region. Beautiful beaches, mountains and an enticing and interesting mix of cultures make the country fascinating for tourism. Azerbaijan is located where Eastern Europe and Russia meet the Orient. Today, the capital Baku is becoming a modern city, although its architecture reflects some shadows of the Soviet past. When considering the favorable natural conditions, the tourism sector should have an important role in developing Azerbaijan's GDP. Unfortunately, only a very small part of it is capitalized. (CESD, 2011, p. 4)

The three project regions are located in different parts of the country with very different characteristics. The regions are Astara-Lankaran, Sheki-Gabala and the Absheron Peninsula (Fig. 1). Based on their strengths and discussions with the local authorities, altogether seven villages (Kish, Vandam, Quala, Kokolos, Rvo and Khanbulan) were chosen for the project to further promote their tourism.

The Astara-Lankaran region is located in favorable environmental conditions, on the Caspian coastal zone bordering Iran. Fertile soil, abundant water and a favorable climate in Lankaran have created a good basis for agriculture, livestock, horticulture, cultivation of medical herbs and tea, gardening of citrus fruits, fisheries, sericulture and bee-keeping. Decorative art is practiced in the region, while traditional arts with jewelry, weaving and carpet weaving, pottery and other arts are widespread. The cuisine of the southern region is ancient and rich.

In the Astara-Lankaran region, three villages - Khanbulan, Rvo and Kokoloswere selected as project villages. The project introduced rural and eco-cultural tourism as a source of income and provided education and training, for example, on tourism entrepreneurship skills, guiding skills, and traditional handicrafts for local entrepreneurs, craftsmen, local residents providing housing services and local tour guides. There are about 6,000 inhabitants in the three villages. Khanbulan village is located in the territory of Hirkan National Park, providing a wonderful opportunity for developing rural and eco-cultural tourism in the park and the surrounding villages. Rvo is situated on the bank of the Lankaran 
Figure 1. Project areas include the southern Astara-Lankaran region, Sheki-Gabala in the western Azerbaijan and the Absheron Peninsula surrounding the capital, Baku (eMapsWorld, n.d.).

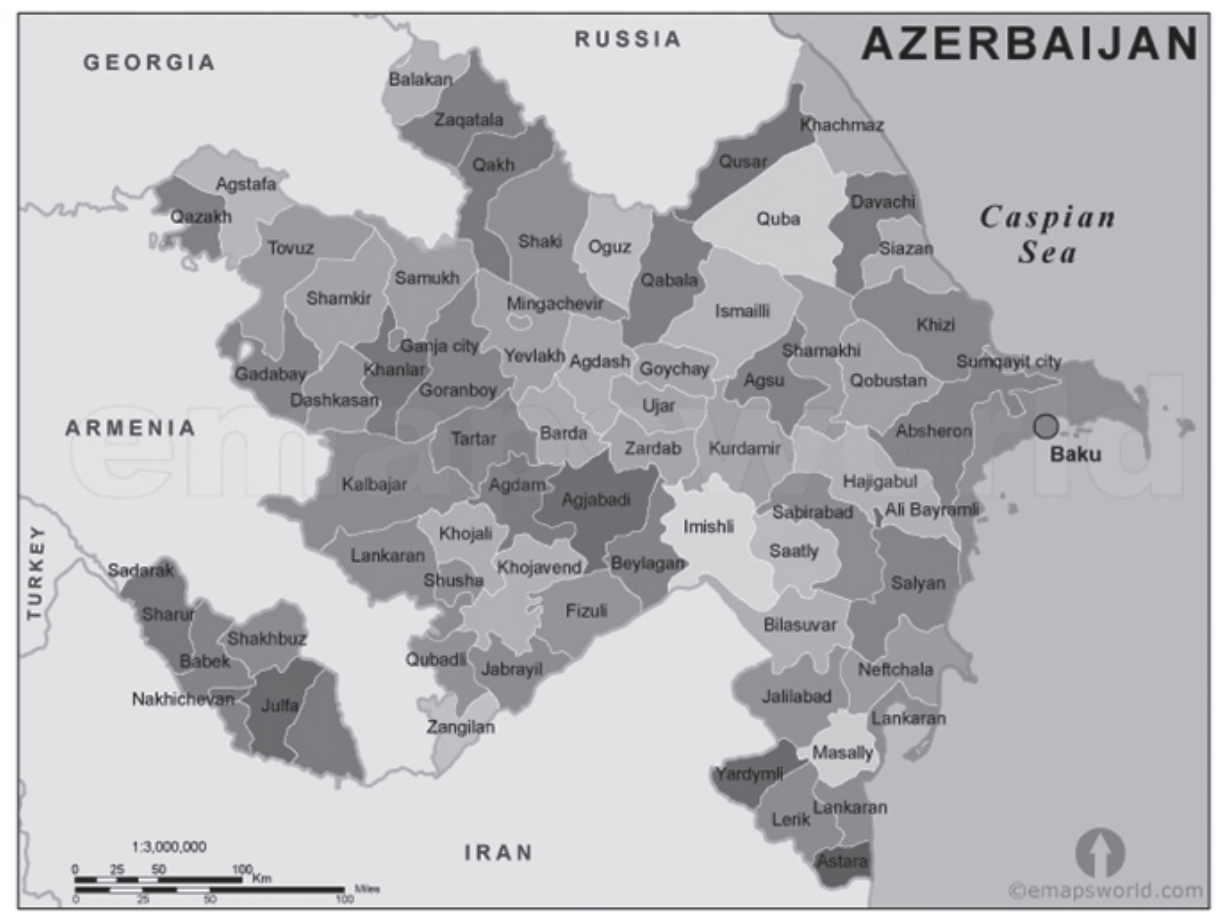

River by the road leading to the Ballabur Tower dating back to the $8^{\text {th }}$ to $9^{\text {th }}$ centuries. The tourist information center in Lankaran and the cultural center in Kokolos have acted as the main hubs in development of marketing materials and channels of the region and as educational facilities in the promotion of conservation of cultural and historical roots of local traditions, respectively.

The Sheki-Gabala region is located approximately $300 \mathrm{~km}$ west of Baku close to the Georgian border. The region is a picturesque mountain area rich in narrow gorges and green valleys, springs, purest rivers, waterfalls, and mineral water springs framed by dense woods and alpine meadows. Sheki was and still is a major city center, which is famous for its craftsmen and merchants. The village of Kish in the district of Sheki and the village of Vandam in Gabala district were selected as the project villages for the development of tourist guidance and tourism entrepreneurship skills. Several houses for home-based accommodation exist in both of the villages.

The third selected region, the Absheron Peninsula, has special importance 
in terms of historical monuments. The Oala village, located northeast of the peninsula, is one of the oldest settlements in Absheron. In 2008, on the initiative of Heydar Aliyev Foundation, the first outdoor archaeological and ethnographic museum complex was created in the territory of Quala Historical and Ethnographic Reserve, where archaeological and architectural monuments were restored. On the Absheron Peninsula, Quala, an old village with highly traditional and religious values, was chosen as the project village. The project activities included raising gender awareness in the community in order to promote the schooling of girls and entrepreneurship of women.

One of the advantages of the project was networking and know-how transfer between different stakeholder groups and promoting the establishment of the Association of Tourist Guides of Azerbaijan. The association will function as a public organization supporting the development of tourist guides who are able to provide guiding services based on a market approach in different parts of the country. Additionally, development of tourist routes (hiking, winery routes, horseback riding, bird-watching, cultural and handicraft routes, historical routes) with consideration to different target groups is ongoing with plans to initiate marketing in summer 2014. The aim of these project activities is to create local organized structures which would create the sustainable basis for needed marketing and communication networks.

During the project implementation (2012-2014), the potential of Azerbaijan as a tourist destination emerged. The majority of tourists, consisting of business travellers, choose to stay in Baku, the capital of Azerbaijan. Tourism is promoted by the government of Azerbaijan aiming to diversify the economy, currently heavily based on gas and oil reserves. Rural tourism and ecotourism is included in the Tourism Strategy of Azerbaijan, yet several fundamental challenges hinder comprehensive development of rural tourism. The challenges came up during the interviews conducted by the students of TUAS in their practical training for the project in Azerbaijan by the project management and during the two evaluations conducted in 2013. This paper presents the observed challenges while also attempting to provide possible solutions to them. 


\section{Methods}

In the course of the project, five students from Finland conducted their practical training for the project in Azerbaijan. The trainings ranged in length from one month to three months. Additionally, the students' educational background varied from environmental technology to sustainable development and business administration. Among other tasks, the students interviewed target groups in the project regions, focusing on Sheki-Gabala and Astara-Lankaran. The interviewed people consisted of hotel workers, handicraft masters, providers of home-based accommodation and local authorities of the field.

In 2013, two semi-internal evaluations on the project were conducted. First, a team of five people visited the Astara-Lankaran region in April 2013. The evaluation team consisted of representatives from Sustainable Future NGO, TUAS and another development cooperation project implemented in Azerbaijan, accompanied by the project manager. As an outsider to the project, the goal of the evaluation team was to assess the project plan, its objectives and anticipated results, and to compare those to the activities implemented, taking into consideration the content and results of the project so far. The methods used for the evaluation included reading project materials, observations, guided discussions, and interviews with project partners and stakeholders (Heikkilä, 2013, pp. 7-9).

The second evaluation was carried out in October 2013, focusing on the ShekiGabala region. The evaluator had decades of personal experience in Azerbaijan and thus was familiar with the culture and customs of the country. In the AstaraLankaran region, the evaluator accompanied the TUAS students' study group but in the Sheki-Gabala region made a separate evaluation visit. The aim was to meet with the partners, stakeholders and beneficiaries in order to discuss the project implementation (Oksanen, 2014, p. 2). The evaluators interviewed the head of Internal Tourism Development and the regional representative of Gabala from the Ministry of Culture and Tourism, the director of Lankaran Tourist Information Center, the vice-rector of Baku Tourism Institute and the head of a local NGO Shafak Ecotourism Public Union. Shafak is an active and well-known organization in the field of sustainable tourism in the Astara-Lankaran region. They have implemented several projects which include education of local municipalities on ecotourism and training for rural households on tour guiding.

All of the conducted interviews by the students and the evaluators were qualitative. Therefore, they give a rather limited view of the overall picture of rural tourism 
in Azerbaijan. Yet, the interviewees were from different stakeholder groups, thus representing different backgrounds and points of view. Another limiting factor was the language. Even though some interviews could be conducted in English, the majority of them were translated by a local member of the project staff, or on occasion by an outsider to the project. As the interpreters used were not professionals, it is possible that some things may not have been translated or the message was slightly altered in the process.

\section{Results}

Both the conducted evaluations and the students' interviews yielded similar findings. Moreover, the discovered challenges and areas in need of development were somewhat similar among the interviewees. The answers from the interviewees are presented below.

The number of tourists in Azerbaijan has increased rapidly during the past decade or so. In 2000, approximately 600,000 tourists traveled in the country, while in 2012 the number was already 2.4 million. Hence, the annual increase was 10 per cent. Most of the visitors were business travelers, while holiday tourists make up only about 20 per cent of the total number. Approximately 10,000 employees work in the tourism industry and 50 new hotels are currently under construction, owing to the promotion of the tourism sector and yearly increases of tourists, even though mass tourism does not exist yet. There are 514 hotels and 218 travel agencies in Azerbaijan, but the tourism focuses at the moment in the country's bigger cities, due to lack of sufficient information about historical and cultural attractions preserved in the villages. More than half of the hotels are located in Baku, indicating a substantial increase, considering that twenty years ago there were only two hotels. The Tourism Institute was established in 2006 in order to answer to the quickly increasing numbers of tourists and their needs. Currently, five new vocational schools are planned, as a result of the high demand of professionals for the industry (Oksanen, 2014, p. 6). The potential of rural tourism, ecotourism, socially responsible tourism and also bed and breakfast type of accommodation was raised. Nevertheless, the need for professionals in tourism and development of the information centers in the rural areas was acknowledged as well (Heikkilä, 2013, pp. 13-14).

The Ministry of Tourism and Culture acknowledges rural tourism in its Tourism Development Strategy and supports the areas and implemented projects for rural tourism based on it. Tourist information centers in rural areas are partly 
funded by the ministry. This funding is allocated to salaries and overheads while the development of operations, material and marketing has to be funded by the centers themselves. The ministry is currently supporting five centers, which were established in 2005 through the cooperation of the United Nations Development Programme (UNDP) and the government, due to their lacking links with companies, insufficient sales of products and scarce fundraising of its own. In the future, the tourist information centers are expected to operate on their own (Heikkilä, 2013, pp. 14, 16).

The importance of rural markets, the ability of the local people to sell their products and the selling of especially "green products" is acknowledged by the ministry. The role of the NGOs was expressed in building the capacities of rural entrepreneurs and in listening to the youth and the rural communities in general. Among the challenges of rural tourism, insufficient infrastructure, lack of commercialization and the scant promotion of tourism services and activities were named. The need for stronger cooperation between the actors within the tourism industry was expressed, and so was the short tourist season, which could hinder obtaining resources and decrease motivation for product and service development (Heikkilä, 2013, pp. 14-15).

As the representative of the ministry saw the importance of the role of NGOs in developing rural tourism, so did the local NGO. According to an interviewee, the challenge is that the rural people do not know how to organize the sale of their products or services and how to increase their markets.

Lankaran Tourist Information Center is visited by approximately 1,000 tourists during the two-month-long tourist season. Approximately 17,000 tourists, mostly national tourists, visit Lankaran during the summer months. Lankaran is said to appeal to tourists due to its mountainous scenery and hot springs, with activities such as hiking, horse-riding, camping, fishing and bird-watching. However, no promotional materials, maps of the area, or contact details for the services are available at the center. The evaluation team also visited several options for home-based accommodation, which were found to be impossible to find without knowledge of the region, local people, and local language skills. According to the director of the tourist information center, the current issues in the tourism industry relate to a lack of marketing materials and to the tourism and service culture of Azerbaijan, which is still developing (Heikkilä, 2013, pp. 16-17).

The number of tourists both in Gabala and Sheki reached approximately 5,000 in 2013 (Oksanen, 2014, p. 7). Compared to Astara-Lankaran, the development of infrastructure and services has been more rapid in Gabala-Sheki. There is no 
tourist information center in Gabala yet, but in Sheki it is more organized with premises for local handicrafts to produce and sell their products in addition to its centered location close to the most popular sights. In terms of handicraft entrepreneurs, the project has been promoting the transmitting of traditional skills and culture to the youth of the project areas from the local masters. The challenge is that the youth are unmotivated to continue with traditional handicrafts due to lacking markets as future source of income. Furthermore, women's role in a male-dominated culture is perceived as caretakers of the household instead of managing businesses. Especially entrepreneurship in handicrafts is unappreciated and perceived as a disrespected livelihood. Such an attitude discourages the current handicraftsmen and -women and decreases the appeal for new entrepreneurs.

The questions asked during the interview were mainly focused on investigating the needs of local communities in developing tourism and handicraft art in the area and clarifying the barriers (legal, economic, cultural, etc.) for developing sustainable rural tourism in project target regions.

The main problem is the lack of skilled labor force, and therefore the quality of services is often low. Road conditions, water and sanitation infrastructure are not well developed in many locations. Though sea sand has invaluable therapeutic importance, there are insufficient infrastructures to promote sea tourism business in this area.

The main recommendation based on outcomes from the interviews were:

1) Development of training modules and "training of trainers" in project target regions for tour guiding and tourism entrepreneurship skills.

2) Development of efficient marketing of rural tourism for Azerbaijan and development of different tourist routes based on customer requirements.

3) Development of a value chain for tourism at national and regional level in Azerbaijan.

4) Development of a modern communication system for promoting efficient tourism business. 


\section{Conclusions}

The tourism industry in Azerbaijan is currently undergoing a revitalization and rejuvenation process. Citizens Development Corps (2004, p. 4) reported that prior to independence, central planners from the Soviet Union made significant investments in the Azerbaijani tourism sector-primarily in hotels, transport facilities, museums, and other tourist attractions. As a key tourist destination within the Soviet Union, Azerbaijan benefited from the tangible assets acquired from this investment. However, the central planning approach did little to promote or encourage the development of the non-tangible assets (such as innovation, creativity, flexibility, customer service, etc.) that are needed to be competitive in the global tourism market. Thus, after Azerbaijan gained its independence, the key players in the industry did not have the capacity or knowledge needed to market the country and its attractions as a unique tourist destination.

Rural tourism, still a minority tourism market, is making a valuable contribution to rural economies. Its contribution can be expressed not only in financial terms, but also in terms of jobs, contributions towards funding conservation, encouragement to the adoption of new working practices, and the injection of new vitality into sometimes weakened economies. Rural tourism potentially promises some of the following benefits to rural development: job retention, job creation, new business opportunities, opportunities for youth, service retention, community diversification, preservation of rural heritage and culture, increased sales of arts and crafts, and landscape preservation. Tourism encourages conformity to an ideal image of community, which can result in the growth of personal ties and community solidarity. Thus the basis for community solidarity shifts from shared cultural background to shared image. Amenities play a fundamental role in shaping a community's identity and pride. The potential of tourism for improving the facilities and amenities in the community would have positive implications for community pride, particularly for rural museums as an important repository of rural culture.

There is strong potential for eco- and agro-tourism in Azerbaijan due to the incredible diversity in terrain, climate, flora, and fauna. Efforts should be made not only to further develop the opportunities for mountaineering, birdwatching, fishing, and hiking (among other activities), but also to protect the opportunities themselves. Specifically, trainings should be conducted to transfer the idea of environmental sustainability of these attractions to the locals who run them, so that the sites are not destroyed by the tourists who visit them. Small and medium-sized businesses should be developed to manufacture for 
tourists items of high quality reflecting Azerbaijan identity. These businesses offer the most potential for employing people, especially in the rural areas of the country. Moreover, to ensure quality, workshops should be held that help existing businesses expand and encourage others to start. They should cover production, especially product development, business skills, marketing and joint promotion (European Parliament, 2013, pp. 10-11).

Higher returns could be achieved by both driving more tourists in the area, and by extending their stay period besides the high seasons. These goals could be achieved by setting forth a sustainable rural tourism marketing plan and guidelines to be implemented for the participating areas in pilot locations. In addition, a recognizable brand ought to be designed to clearly identify sustainable rural tourism initiatives which would share the same set of rules for the market attribution and certification process. As a result, the whole rural area will benefit from the increased visitor flow, since it is the area itself that will be part of what is offered to tourists rather than a single location or initiative. Partnerships with local entities, especially with craftsmen and small entrepreneurs producing local foods are essential both for gathering and systematizing the knowledge about the area's landscape, remarkable sites, cultural heritage and characteristics, eno-gastronomical products, and for selecting and properly educating local participating operators.

While service design is no panacea for all the challenges in tourism or rural tourism of Azerbaijan, it enables a holistic end-user approach to tourism services and products. The aim of service design is to integrate the needs of the customer while taking into account the business objectives of the service provider (Fig. 2). The process entails the creation of a service with an original idea and its assessment; service design with actual design, implementation and service production, and service management, during which the service is evaluated and modifications are made if needed (Shostack, 1982).

Azerbaijan is an exotic and safe country with hospitable people and several windows of opportunities for the development of tourism. Many today's tourists find appealing the destinations which give a chance to experience the local culture, people and every-day living, and Azerbaijan can provide that. However, several essential areas are in need of development in order to obtain sustainable rural and eco-cultural tourism. Tourism services for masses is not what should be the aim here, but rather small-scale entrepreneurship, increased income especially for women, and diversification of rural livelihoods. The local communities require support from both regional and national authorities in the promotion of rural development and tourism, and are in need of long- 
Figure 2. Service design provides a holistic approach, combining the needs of the end user and the business objectives of the services provider (Sims, 2010; modified by the authors).

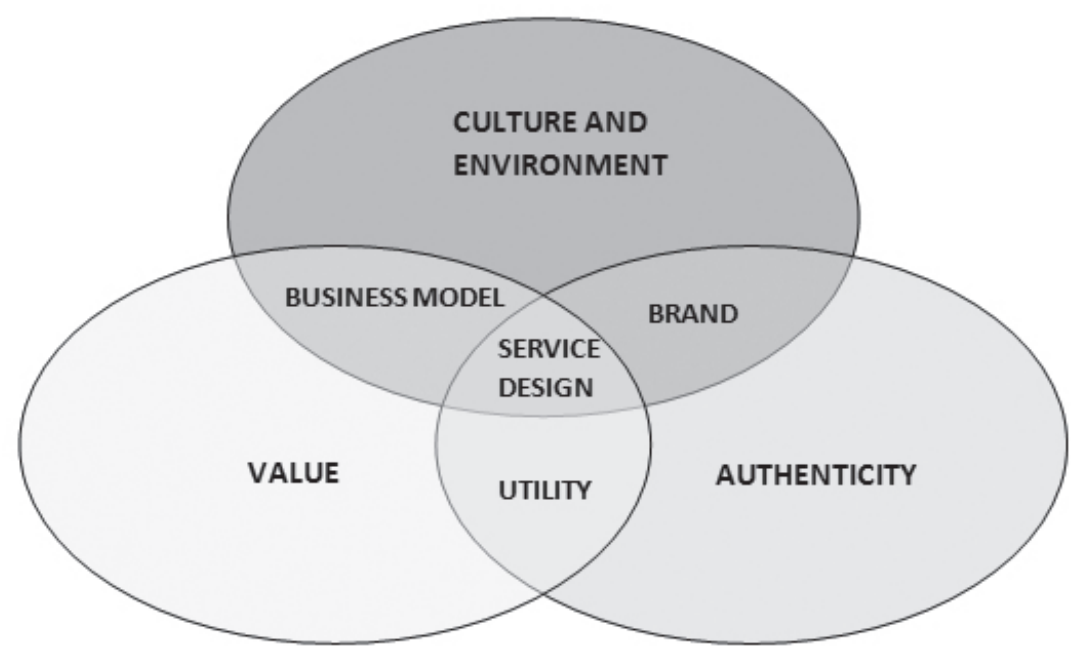

term capacity building in business management and marketing. Moreover, local and country-wide network and cooperation is essential in ensuring consistent marketing of the rural areas for tourists. The organized network of stakeholders should range from national and regional authorities to regional tourist information centers and the entrepreneurs of the rural communities. Additionally, grass-root education on gender awareness is needed for both women and men in order to increase appreciation and permission for female entrepreneurs. Education on the importance and relevance of nature conservation is also required in order to preserve the environment from effects of tourism and to comprehend the relevance of the environment as a factor in eco-cultural tourism based livelihood.

As a general rule, however, rural communities in the target regions of Azerbaijan are challenged to take full advantage of the tourism industry due to the lack of sufficient infrastructure to support year-round visitors.

This is based on the idea that for a community-based ecotourism or community tourism enterprise to be successful, it must do three things:

1) Understand and meet the social and cultural needs of the community;

2) Realistically deliver a long-term quality ecotourism product;

3) Make special efforts to connect these products to international and local markets. 
Tourism is a big sphere regulating vital social and economic operations of the world, enlarging the scope of business interests which create the mutual relations of different countries and nations. Rural and eco-cultural tourism is also revolutionizing businesses and prompting economic development across the globe. Rural tourism has many potential benefits for including employment growth, an expanded economic base, repopulation, social improvement, and revitalization of local crafts. The extent to which these benefits are realized remains the subject of much debate. Certainly, there is evidence to support the claim that, as a vehicle of economic growth and diversification, tourism can make an important contribution to rural incomes both at the level of tourism operators and more widely in the local economy.

Jonna Heikkilä works as a project manager at the Turku University of Applied Sciences Ltd. (TUAS), Finland. She manages the project called 'Development of Sustainable Entrepreneurship and Support of Local Handicrafts in Rural Azerbaijan', one of her development cooperation projects. Since 2011, her areas of work at TUAS have focused on environmental health, development issues, and participatory empowerment and inclusion of people

Aytan Poladova, Ph.D. is an environmental engineer in environmental conservation, development of environmental management and mitigation plans, sustainable tourism with more than 15 years of experience in working with international organizations and programs. She is the director of Ekoloji Tarazliq public environmental organization in Azerbaijan, where she coordinates projects aiming to strengthen public environmental awareness, rural tourism, water resources protection and sustainable sanitation. She is the author of publications on the development of water safety plans, sustainable tourism, environmental monitoring of gas and oil pipelines and many others.

Juha Kääriä, Ph.D. is a specialist in applied environmental sciences and he has more than 25 years of working career. He has over 60 publications on these topics, many of them in international journals. Since 2004, he has been working at the Turku University of Applied Sciences as R\&D Manager in the Faculty of Technology, Environment and Business. His main duty is to lead a wide environmental expertise programme financed mainly by different EU financial programmes and national fundings. 


\section{References}

Cater, E. (2001), 'Ecotourism,' in N. J. Smelser \& P. B. Baltes (eds.) International encyclopedia of the social \& behavioral sciences, Amsterdam: Elsevier, pp. 4165-4168. http://dx.doi.org/10.1016/B0-08-043076-7/02566-3

CESD (2011), Policy Report on Tourism Sector in Azerbaijan, Baku: Center for Economic and Social Development. Retrieved from http://cesd.az/new/wp-content/ uploads/2011/07/CESD-Tourism-Paper.pdf [accessed 31 Mar 2014]

CDC (2004), Rapid Tourism Assessment for the Azerbaijan Sector Development Program, Baku: Citizens Development Corps, pp. 4-7. Retrieved from http://www.osce.org/baku/27857?download=true [accessed 31 Mar 2014]

Dimitrovski, D.; Todorovic, A. \& Valjarevic, A. (2012), 'Rural tourism and regional development: Case study of development of rural tourism in the region of Gruža, Serbia,' Proceedings of conference 'Landscape, Environment, European Identity', 4-6 November 2011, Bucharest. Procedia Environmental Sciences, vol. 14, pp. 288-297. http://dx.doi.org/10.1016/j.proenv.2012.03.028

Donohue, H. \& Needham, R. (2006), 'Ecotourism: the evolving contemporary definition,' Journal of Ecotourism, vol. 5, no. 3, pp. 192-210.

http://dx.doi.org/10.2167/joe152.0

Ecotourism in America (n.d.), Terms and Definitions. Retrieved from http://www. ecotourisminamerica.com/tools/definitions/ [accessed 31 Mar 2014]

eMapsWorld (n.d.), Map of Azerbaijan, eMapsWorld Online. Retrieved from http://www.emapsworld.com/azerbaijan-map.html [accessed 31 Mar 2014]

European Parliament (2013), Industrial heritage and agri/rural tourism in Europe, Policy Department B: Structural and Cohesion Policies, Transport and Tourism. Retrieved from http://www.europarl.europa.eu/studies [accessed 31 Mar 2014]

Heikkilä, J. (2013), Development of Sustainable Entrepreneurship and Support of Local Handicrafts in the Rural Azerbaijan: Project Mid-term Evaluation Report, Turku: Turku University of Applied Sciences, no. 184.

Higham, J. E. S. (2007), 'Ecotourism: competing and conflicting schools of thought,' in J. Higham (ed.) Critical Issues in Eco-tourism: Understanding a Complex Tourism Phenomenon, Oxford: Butterworth Heinemann, pp. 1-19.

http://dx.doi.org/10.1016/B978-0-7506-6878-1.50005-0

Irshad, H. (2010), Rural Tourism: An Overview, Alberta: Government of Alberta, Agriculture and Rural Development. Retrieved from http://www1.agric.gov. ab.ca/\$Department/deptdocs.nsf/all/csi13476/\$FILE/Rural-Tourism.pdf [accessed 31 Mar 2014]

Oksanen, L. (2014), Development of Sustainable Entrepreneurship Approaches and Supporting of Local Handmade Handicrafts Arts in Rural Areas of Azerbaijan, 
Evaluation report, Fall 2013, Unpublished report of Turku University of Applied Sciences.

Shostack, L. G. (1982), 'How to Design a Service,' European Journal of Marketing, vol. 16, no. 1, pp. 49-63. http://dx.doi.org/10.1108/EUM0000000004799

Sims, P. (2010), Service Design Goes Mainstream [Weblog]. Retrieved from http:// madebymany.com/blog/service-design-goes-mainstream [accessed 31 Mar 2014] Sustainable Travel International (n.d.), 'The Effects Mass Tourism Has Had on Developing Countries,' Responsible Travel Report. Retrieved from http://www. responsibletravelreport.com/component/content/article/2642-mass-tourismeffects [accessed 31 Mar 2014]

United Nations (1987), Our Common Future. Report of the World Commission on Environment and Development: UN documents. Retrieved from http://conspect. nl/pdf/Our_Common_Future-Brundtland_Report_1987.pdf [accessed 31 Mar 2014]

Weaver, D. B. \& Lawton, L. J. (2007), 'Progress in tourism management. Twenty years on: the state of contemporary ecotourism research,' Tourism Management, vol. 28, pp. 1168-1179.

http://dx.doi.org/10.1016/j.tourman.2007.03.004

World Tourism Organization (1998), Guide for Local Authorities on Developing Sustainable Tourism, Madrid: World Tourism Organization.

— (2013), East Asia \& Pacific: Tourism 2020 Vision, vol. 5. Retrieved from http://pub. unwto.org/WebRoot/Store/Shops/Infoshop/Products/1189/1189-1.pdf [accessed 31 Mar 2014]

Ying, T. \& Zhou, Y. (2007), “Community, governments and external capitals in China's rural cultural tourism: A comparative study of two adjacent villages," Tourism Management, vol. 28, pp. 96-107. http://dx.doi.org/10.1016/j.tourman.2005.12.025 